\title{
Effect of Educational Counselling Program on Academic Adjustment for Faculty of Physical Education Students
}

\author{
PROF. DR / Magda Mohamed Ismail
}

Faculty of Physical Education - Helwan University

PROF. DR / Mona Mokhtar Almorsi

Faculty of Physical Education - Helwan University

DR / Eman Mostafa EL SHanawany

Faculty of Physical Education - Helwan University

Researcher / Nesma Gamal Abdalla

Faculty of Physical Education - Helwan University

\section{Introduction and Research Problem}

The university stage represents the top of the educational hierarchy, being different from the previous stages in terms of means and goals, and because life inside the campus differs from that in high school. University is a community of cultured people where the student will not realize his own self except among the company of those who share with him this community. That's why it is essential for him to get to know his position within this community, his role in achieving his goal, and the means helping him be an active member and interact with the elements of this community, and go through this stage successfully achieving the desired goal. (Sandra Meriden: $7,8)$.

Counselling is considered a ring completing the chain of educating and learning, as it makes the educational or scientific process more effective. It 
takes part in fully preparing the students, helping them in liberating their potential energies so as to benefit from their abilities and potentials, overcoming their problems and thus leading to the achievement of adjusting with their environment. (Al-Tamimi: 17).

Modern education holds counselling process as a part and parcel of it. The relationship between education and counselling is an integrative reciprocal one; counselling includes both teaching and learning processes in changing behavior; education includes the process of guidance and counselling. Educational institutions around the world are considered as the vital active field of counselling. The relationship between counselling and the goals of education depends on various educational factors, as the educational process has to be one of a guidance and counselling in the first place, in order to help the students choose, take decisions, reveal their needs, evaluate their abilities and potentials, and fulfill their desires. Also to help them adapt their needs with the culture of the society they live in. (AlHarira and Al-Emamy: 52, 54).

Educational counselling is the process of helping the individual in making educational plans accommodating with his abilities, interests, and goals. To choose the type of studying, proper curricula, and subjects that help him discover the educational potential beyond the present educational level, succeed in his educational program, and diagnose and solve educational problems in a way that achieves his educational adjustment in general. (Zahran: 377).

Sports psychological guidance and counselling depends on the developmental approach, seeking to increase the efficiency and achieve the highest level possible of adjustment and psychological health, and on the 
preventative approach that focuses on preventing the problems before taking place. (El-Araby Shamoun \& Magda Ismail:17,18)

"Abu Asaad, 2009" defines educational counselling as "the process of helping the student learn the limits of his potentials, in order to use and invest them properly and effectively in choosing the appropriate education, to join and succeed in it, and overcome the academic difficulties hindering his growth or academic life, achieving the suitable psychological and social adjustment". (Abu Asaad: 272).

Adjustment with university life is considered a prerequisite for the students' success and continuity in their university education. The students' adjustment with university life is an indication of their general adjustment. Whereas poor adjusting to university life refers that there are unsatisfied needs among students within the university environment, resulting in low performance during the education period and beyond. University for students is considered a new experience, different from previous educational ones; there are many problems and new experiences they need to go through, face, and adjust to them. For example, learning the university's systems and regulations, also choosing a major and adjusting to it, selecting a career and preparing for the future job, and what follows of taking important decisions to the students' future and their academic lives. (Al-Abidi: 44, 46).

Academic adjustment is considered as individual ability to manage its social challenges, psychologist, and its knowledge when experiencing a transition to college life. Individuals that succeed in academic adjustment will show the success in academic lifestyle, academic achievement, and academic motivation (Anderson, Guan, \& Koc, 2016). 
The need for guidance, counselling, and helping university students in the different levels is obvious, as the student moves to a different society from which he was familiar with in the pre-university stages, getting prepared for a more meaningful serious role. (Mai Moussa: 227). Educational counselling is considered as the passage to ensuring the students' success in their academic program, and helping them take the right decisions through their working life after graduation. Counselling helps in motivating and encouraging students, it provides them with experience and deepens the relationship and trust with the counsellor in particular, and the professors and department in general. The lack of experience for some students (especially those who recently joined the academic program) is the main reason in their inability or unwillingness to study, which may lead them to leave the university. (Al-Harira and Al-Emami: 179).

Being an Assistant Teacher in Faculty of Physical Education for Girls and through her direct contact with the students in different academic years, the researcher noticed many negativities that began to appear noticeably on the behavior of a remarkable number of students. Such as, irregularly attending lectures, non-commitment to the lectures' schedules, low response to instructions, lack of interest in preparing and effective participation in lectures, tendency to present individual researches and distancing from group research, constant stress and fatigue, and constant criticism of the nature of studying in Faculty of Physical Education.

As the nature of studying in Faculty of Physical Education differs from other faculties, in terms of the need to exert physical effort in addition to basic academic skills, this results in increasing the stress, leading to the emergence of adjustment problems for students, and thus having a negative impact on their academic achievement and success. The importance of this study is represented as an attempt by the researcher to design an 
educational counselling program according to the cognitive behavioral theory and follow the cognitive restructuring strategy to develop the students' academic, psychological, and social skills, in order to help them improve their academic adjustment.

\section{Research Aim}

This study aimed at identifying the effect of educational counselling program on academic adjustment for Faculty of Physical Education students.

\section{Hypothesis}

There are statistically significant differences between pre and post measurements for the research sample on the (adjustment with university life scale) for the post measurement.

\section{Key Words}

\section{Educational Counselling}

The researcher defines it as "the process of helping female students in overcoming difficulties that crosses their academic path, and facing the problems in the academic environment through discovering their potentials and abilities, and providing them with the sufficient information to achieve the psychological, social, and academic adjustment in the way that fulfills their educational adjustment in general". (Operational Definition)

\section{Academic Adjustment}


"Waslullah, 2011" defines academic adjustment as "the extent of the student's accustoming with the entire fields of the academic, psychological and social university environment. This can be achieved through his pursuits in fulfilling his goals, shaping and precisely defining them, and making proper plans to fulfill them by learning his personal abilities and the university environment components.

The researcher defines it as "the results scored by female students on the adjustment with university life scale."(Operational Definition)

\section{Plan}

\section{Methodology}

The researcher used the experimental method as it suits the research's nature, using pre-test and post-test single-group design.

\section{Population and Sample}

\section{Research Population}

The population of this research consists of (595) second year female students of the academic year 2019/2020, Faculty of Physical Education for Girls, Helwan University.

\section{Pilot Study Sample}

The pilot study sample was randomly chosen aiming at extracting scientific coefficients of (99) students from the same research population.

\section{Main Study Sample:}

In order to define the main study sample for applying the educational counselling program, the researcher applied (adjustment with university life scale) on a sample of (220) students. The main sample was chosen to apply the program on a sample of (14) students who had a low score on the scale and were willing to participate in the program. 


\section{Table (1)}

Statistical description of the research sample in (adjustment with university life scale)

\begin{tabular}{|c|c|c|c|c|c|c|c|c|}
\hline \multirow[t]{2}{*}{ Fields } & \multirow{2}{*}{$\begin{array}{l}\text { Measurin } \\
\text { g Unit }\end{array}$} & \multirow[t]{2}{*}{$\bar{X}$} & \multirow[t]{2}{*}{$\mathbf{S}$} & \multirow[t]{2}{*}{$\propto_{3}$} & \multicolumn{2}{|c|}{ Normality } & \multicolumn{2}{|c|}{ Randomization } \\
\hline & & & & & Z & $\begin{array}{c}\text { P(value } \\
\text { ) }\end{array}$ & Z & $\mathrm{P}($ value $)$ \\
\hline Academic & degree & 39.21 & 6.65 & -0.13 & $0.62^{*}$ & 0.84 & $-0.20^{\star}$ & 0.84 \\
\hline $\begin{array}{l}\text { Psycholog } \\
\text { i-cal }\end{array}$ & degree & 47.00 & 6.05 & 0.11 & $0.47^{*}$ & 0.98 & $-1.39^{*}$ & 0.16 \\
\hline Social & degree & 37.14 & 7.50 & -0.19 & $0.52^{*}$ & 0.95 & $1.99^{\star}$ & 0.10 \\
\hline Total Scale & degree & $\begin{array}{c}123.3 \\
6\end{array}$ & $\begin{array}{c}14.1 \\
7\end{array}$ & -0.05 & $0.86^{*}$ & 0.45 & $-0.28^{*}$ & 0.78 \\
\hline
\end{tabular}

*indication of $(P)$ value $\geq(0.05)$

Table (1) shows the arithmetic mean, standard deviation, and skewness coefficient of the research sample in (adjustment with university life scale). The data indicate that the values of skewness coefficient of the research sample are limited between $( \pm 3)$, indicating the normality of data for the sample population on (adjustment with university life scale). 


\section{Data Collection Tools:}

Adjustment with university life scale, developed by "Yahia Daoud" (2001).

\section{Scale Description:}

The original scale consists of (51) items, measuring (3) fields, which are (academic, psychological, and social fields) agreeing with Waslullah AlSawat (2011), Khaled Al-Zaioud (2015), Saleh and Tha'er (2008), and Ibrahim Al-Sarayrah (2016) studies. (8) Items were excluded, so the scale final version consisted of (43) items, divided into (14) academic field items, (17) psychological field, and (12) social field.

\section{Scientific Coefficients of the Adjustment with University Life Scale}

The researcher applied Adjustment with university life scale on the pilot study sample of (99) second year female students of Faculty of Physical Education. They were chosen randomly aside from the main study sample, after preparing the scale instructions and the scoring.

\section{Validity Coefficient}

The researcher used the validity of internal consistency to prove the validity of the scale by calculating correlation coefficient between each item and its aspect, and between each aspect and the total scale score. Table (2) 
Table (2)

Correlation coefficient between each item and its aspect, and between each aspect and the total scale score for the (Adjustment with university life scale)

$(\mathrm{N}=99)$

\begin{tabular}{|c|c|c|c|c|c|c|}
\hline \multirow[t]{2}{*}{ No. } & \multicolumn{2}{|c|}{ Academic Field } & \multicolumn{2}{|c|}{$\begin{array}{c}\text { Psychological } \\
\text { Field }\end{array}$} & \multicolumn{2}{|c|}{ Social Field } \\
\hline & $\mathbf{R}$ & P-(Value) & $\mathbf{R}$ & P-(Value) & $\mathbf{R}$ & P-(Value) \\
\hline 1 & $0.20^{*}$ & 0.05 & $0.37^{*}$ & 0.00 & $0.55^{\star}$ & 0.00 \\
\hline 2 & $0.41^{*}$ & 0.00 & $0.41^{*}$ & 0.00 & $0.56^{*}$ & 0.00 \\
\hline 3 & $0.36^{*}$ & 0.00 & $0.37^{*}$ & 0.00 & $0.69^{*}$ & 0.00 \\
\hline 4 & $0.34^{*}$ & 0.00 & $0.47^{*}$ & 0.00 & $0.73^{*}$ & 0.00 \\
\hline 5 & $0.37^{*}$ & 0.00 & $0.58^{*}$ & 0.00 & $0.60^{*}$ & 0.00 \\
\hline 6 & $0.50^{*}$ & 0.00 & $0.43^{*}-$ & 0.00 & $0.59^{*}$ & 0.00 \\
\hline 7 & 0.13 & 0.19 & $0.53^{*}$ & 0.00 & $0.48^{*}$ & 0.00 \\
\hline 8 & $0.27^{*}$ & 0.01 & $0.55^{\star}$ & 0.00 & $0.46^{*}$ & 0.00 \\
\hline 9 & $0.53^{*}$ & 0.00 & $0.66^{*}$ & 0.00 & $0.52^{*}$ & 0.00 \\
\hline 10 & $0.41^{*}$ & 0.00 & $0.72^{*}$ & 0.00 & $0.32^{*}$ & 0.00 \\
\hline 11 & $0.50^{*}$ & 0.00 & $0.54^{*}$ & 0.00 & $0.49^{*}$ & 0.00 \\
\hline 12 & $0.52^{*}$ & 0.00 & $0.56^{*}$ & 0.00 & $0.47^{*}$ & 0.00 \\
\hline 13 & $0.51^{*}$ & 0.00 & $0.63^{*}$ & 0.00 & $0.50^{*}$ & 0.00 \\
\hline 14 & $0.53^{*}$ & 0.00 & $0.32^{*}$ & 0.00 & $0.43^{*}$ & 0.00 \\
\hline 15 & & & $0.48^{*}$ & 0.00 & & \\
\hline 16 & & & $0.55^{\star}$ & 0.00 & & \\
\hline 17 & & & $0.70^{*}$ & 0.00 & & \\
\hline Aspect & $0.71^{*}$ & 0.00 & $0.86^{\star}$ & 0.00 & $0.78^{*}$ & 0.00 \\
\hline
\end{tabular}

*indication of $(P)$ value $\leq(0.05)$ 
Table (2) results indicate statistically significant correlation coefficients between each item and its aspect, as well as between each item and the scale as a whole, which refers to the validity of the scale. Item number (seven) for the academic field was excluded.

\section{Reliability Coefficient}

The researcher used test-retest method with an interval of (15) days between the first and second application of the scale, as shown in Table (3).

\section{Table (3)}

Correlation coefficient between first and second application of (adjustment with university life scale)

$(\mathrm{N}=99)$

\begin{tabular}{|l|c|c|c|c|c|c|}
\hline \multirow{2}{*}{$\begin{array}{l}\text { Scale } \\
\text { Aspects }\end{array}$} & \multicolumn{2}{|l|}{ First Application } & \multicolumn{2}{l|}{$\begin{array}{l}\text { Second } \\
\text { Application }\end{array}$} & r & \multicolumn{2}{l|}{$\begin{array}{l}\text { P- } \\
\text { (Value) }\end{array}$} \\
\cline { 2 - 6 } & $\overline{\boldsymbol{X}}$ & $\boldsymbol{S}$ & $\overline{\bar{X}}$ & $\boldsymbol{S}$ & & \\
\hline $\begin{array}{l}\text { Academic } \\
\text { Field }\end{array}$ & 45.68 & 5.90 & 46.32 & 7.47 & $\mathbf{0 . 6 7}^{\star}$ & 0.00 \\
\hline $\begin{array}{l}\text { Psychological } \\
\text { Field }\end{array}$ & 57.40 & 10.08 & 59.88 & 10.91 & $\mathbf{0 . 8 4}^{\star}$ & 0.00 \\
\hline $\begin{array}{l}\text { Social Field } \\
\text { Total Scale }\end{array}$ & 45.88 & 7.71 & 46.32 & 7.40 & $\mathbf{0 . 7 9}^{\star}$ & 0.00 \\
\hline
\end{tabular}

*indication of $(P)$ value $\leq(0.05)$

Table (3) results indicate statistically significant correlation coefficients between the first and second application in all aspects of (adjustment with university life scale), signifying the reliability of the scale. 


\section{Scale Scoring:}

The researcher used a five-point scale (totally agree, agree, somehow agree, disagree, and totally disagree). The student scores according to his

choice: (5) totally agree, (4) agree, (3) somehow agree, (2) disagree, (1) totally disagree for the positive items. The opposite was used for the negative items: (1) totally agree, (2) agree, (3) somehow agree, (4) disagree, (5) totally disagree. Score is collected, and the total score of the scale ranges between (43-215) degrees, and the student is considered academically adjusted when scored $66 \%$ or more.

\section{Designing Educational Counselling Program}

The researcher developed educational counselling program according to cognitive behavioral theory to help students improve academic adjustment. Seven experts in sports psychology reviewed the application form for the educational counselling program, in order to determine the appropriateness and adequacy of the program's aspects. The researcher concluded three aspects of the program, which are (academic, psychological, and social fields). The program consisted of (34) counselling sessions divided into (24) group sessions and (10) one to one sessions, in a period of eight weeks, three sessions per week, each session is (45) minutes. 
The counselling sessions included training students on academic, social and psychological skills related to studying at the faculty, using the techniques of cognitive behavioral counselling as it suits the nature of the research and the sample of the program.

\section{Procedures:}

\section{Pre measurements}

The researcher applied the pre measurements on the research's main sample of (14) students of the second year, Faculty of Physical Education, on $30 / 09 / 2019$.

\section{Applying Educational Counselling Program}

The researcher applied the educational counselling program on the experimental group for a period of (8) weeks, (3) sessions per week, from (12/10/2019) to (02/12/2019), total of (34) sessions; (24) group sessions and (10) one to one sessions, each session duration was (45) minutes.

\section{Post measurements}

Post measurements were applied directly after completing the application of the educational counselling program on the research sample for (adjustment with university life scale), on (02/12/2019), considering the same conditions and circumstances followed in the pre measurements.

\section{Data Statistical Processing:}


The researcher used SPSS program to calculate the following statistical processing:

- Arithmetical average $\left(X^{\top}\right)$

- Standard deviation (s)

- Correlation coefficient ( $r$ ) Spearman

- Non-parametric differences significance (z) Test

\section{Results:}

Verifying the aim of the research and its hypotheses, the researcher reviews the findings as follows:

\section{Table (4)}

Significance of Differences between pre and post measurements of the study sample in (adjustment with university life scale)

\begin{tabular}{|c|c|c|c|c|c|c|c|c|c|}
\hline \multirow[t]{2}{*}{ Fields } & \multirow{2}{*}{$\begin{array}{c}\text { Scale } \\
\text { Unit }\end{array}$} & \multicolumn{2}{|c|}{ Pre } & \multicolumn{2}{|c|}{ Post } & \multirow[t]{2}{*}{ Difference } & \multirow[t]{2}{*}{$t$} & \multirow{2}{*}{$\begin{array}{c}\mathbf{P} \\
\text { (value) }\end{array}$} & \multirow{2}{*}{$\begin{array}{c}\text { Improvement } \\
\text { Percentage }\end{array}$} \\
\hline & & $\bar{X}$ & $\mathbf{s}$ & $\overline{\bar{X}}$ & $\mathbf{S}$ & & & & \\
\hline Academic & degree & 39.21 & 6.65 & 44.57 & 5.69 & 5.36 & $2.42^{*}$ & 0.03 & $14 \%$ \\
\hline Psychological & degree & 47.00 & 6.05 & 51.07 & 7.99 & 4.07 & $2.15^{*}$ & 0.05 & $9 \%$ \\
\hline Social & degree & 37.14 & 7.50 & 39.86 & 6.98 & 2.71 & -1.19 & 0.26 & $7 \%$ \\
\hline Total Scale & degree & 123.36 & 14.17 & 135.50 & 18.17 & 12.14 & $2.48^{*}$ & 0.03 & $10 \%$ \\
\hline
\end{tabular}

${ }^{*}$ indication of $(P)$ value $\leq(0.05)$

Table (4) shows statistically significant differences between pre and post measurements for the research sample in (academic, psychological) fields and (adjustment with university life scale) as a whole for post measurements. and there are no statistically significant differences 
between pre and post measurements for the research sample in the social field. Improvement percentages ranging between (7\%-14\%).

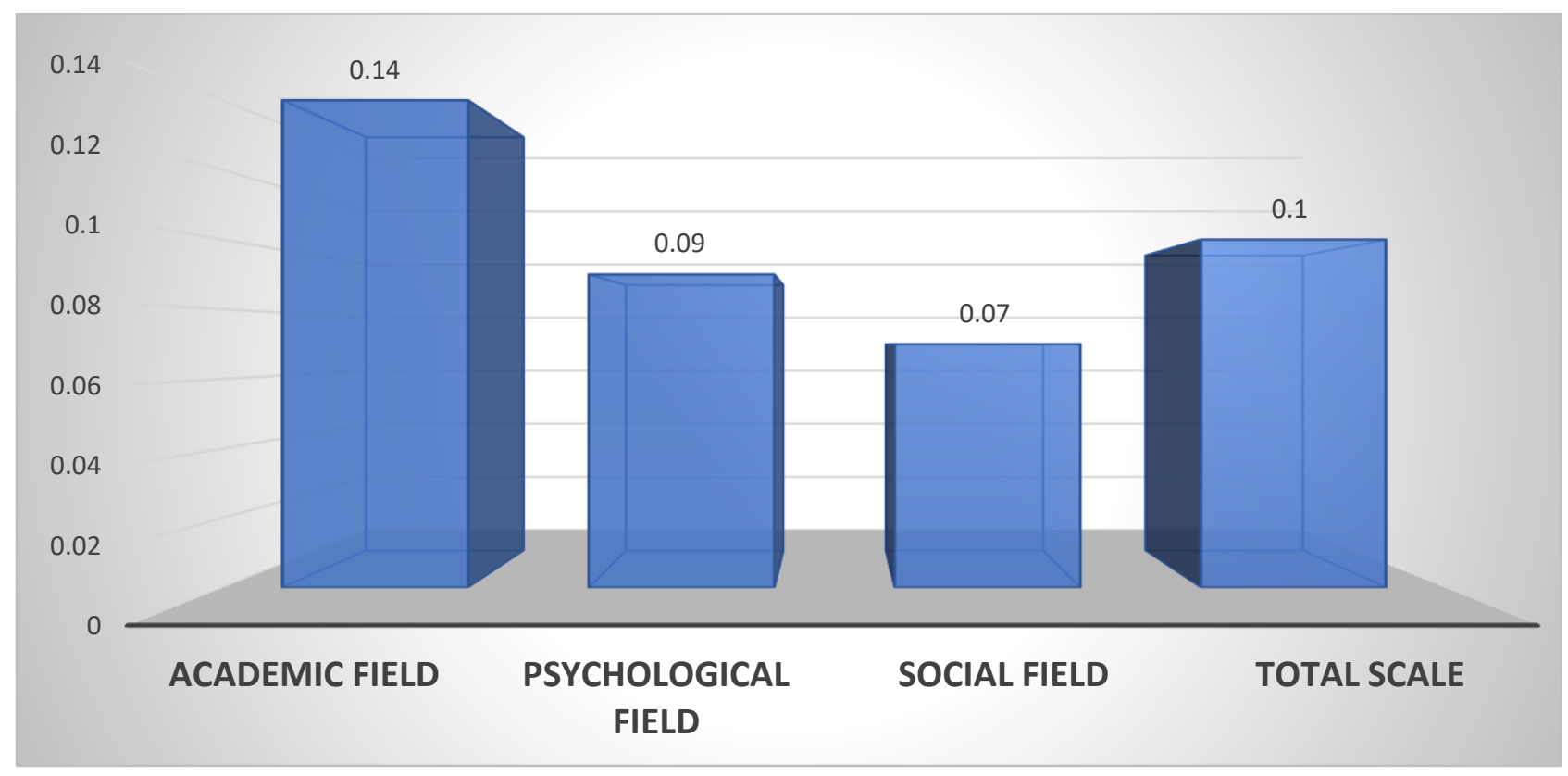

Figure (1)

Improvement percentages between pre and post measurements in adjustment with university life scale

\section{Hypothesis discussion and explanation:}

It is evident from presenting the results of table (4), and figure (1), verifying the validity of the research hypothesis, which states that There are statistically significant differences between pre and post measurements for the research sample on the (adjustment with university life scale) for the post measurement.

The results showed statistically significant differences between pre and post measurements of the research sample in the (academic, psychological) fields, and in (adjustment with university life scale) as a whole for post measurements. The researcher attributes this to the application of educational counselling program sessions, that were based on behavioral 
cognitive theory, which had a positive effect in improving academic adjustment of the second-year students who undergone the program in (academic, psychological) fields. The sessions combined both theoretical and practical aspects, whereas the program included one to one and group sessions to suit the variation of some problems the research sample has. The methods and techniques used in the program varied between (lecture, discussion and dialogue, role-playing, practical activity, homework) in order to achieve the program objectives and to suit the nature of studying in a practical faculty combining physical and mental efforts. The program sessions helped female students developing time management skills, proper warm-up, and stretching and relaxation exercises, thus getting rid of the problem of feeling constant stress throughout the studying period, also, set a schedule for practical training. This resulted in regularly attending lectures and benefiting from the practical application of training on academic achievement skills improved as a result of the program sessions, such as note making, speed reading, effective presentation skills and academic writing. The program's sessions also helped students develop self-esteem, self-confidence and positive self-talk skills, through training on replacing negative thoughts with positive ones.

The results of current study are in agreement with studies by "Ibrahim Juwai'd" (2016), "Basmah Al-Shareef" (2014), "Tha'er Rashid, Saleh Mahdi" (2008), "Firas Al-Qa'dan" (2018), and "Waslullah Al-SAwat, Ghalib AlMasheikhi (2011).

The results also show that there are no statistically significant differences between pre and post measurements for the research sample in the social field of (adjustment with university life scale), and the researcher may refer this to: 
The spread of the bullying phenomenon among the second-year students of the academic year 2019/2020, during which the counselling program was applied, where the researcher noticed repeated complaints of students of the research sample, from being bullied by the rest of their colleagues. Despite the attention shed and interest taken on such issues during the sessions; through giving training on integration and cooperation skills, and making positive relationships with the rest of the colleagues, the continued exposure to embarrassing social situations devoid of cooperation and understanding. This may have formed a psychological barrier for the students- of the research sample- to avoid such situations, and try to rely on themselves, thus do not have sufficient opportunities to apply what they learned in the sessions. The students may need to go through more situations for a full academic year, as the program was applied during one semester only.

The improvement percentages ranged between (7\% -14\%) on the aspects of (adjustment with university life scale), as the academic field recorded the highest improvement percentage (14\%), followed by the psychological field with an improvement percentage (9\%), however the social field scored the lowest improvement percentage of $(7 \%)$. 


\section{Conclusions:}

1. The educational counselling program proved its effectiveness in improving the academic adjustment for the research sample students in both fields (academic, psychological).

2. There are no significant statistical differences between pre and post measurements for the research sample in the social field.

3. Improvement percentage varied between $(7 \%-14 \%)$ on the aspects of (adjustment with university life scale), where the academic field scored the highest rate of improvement (14\%), followed by the psychological field with a rate of improvement $(9 \%)$, however, the social field recorded the lowest percentage of improvement $(7 \%)$.

\section{Recommendations}

1. Using the suggested educational counselling program to improve the academic adjustment of the male and female students of Faculty of Physical Education and other faculties in general.

2. Using educational counselling sessions used in the program, in guidance programs and colleges' guide for freshmen joining Faculties of Physical Education.

3. Taking interest in training the members of the Academic Counselling Unit from the teaching staff in various faculties, through training courses and workshops by specialists in the field of educational counselling.

4. Setting standards for selecting the academic counsellor from the departments of psychology, social psychology and sociology in the faculties, and those who have experience in the field of psychological and educational counselling. 
5. Specifying the first academic week for freshmen, to introduce them to the nature of studying in Faculty of Physical Education, and most important health, psychological and social principles that must be taken into consideration to achieve adjustment to the academic environment.

6. Appointing senior students as guides, under the name of "Guiding Student", and those who want to help freshmen in facilitating problems they might face due to their lack of information.

7. Uploading online scientific materials of the suggested program sessions, attaching it to the student's guide, making it available and easy to access by everyone. 


\section{REFERENCES}

1- Ahmed Abu Asaad (2009): Counselling Psychology, Al-Masirah Publish House, Jordan.

2- Ahmad Sholeh and Nur Widiasmara (2018), "Social Interaction Anxiety and Academic Adjustment", Arts \& Education International Research Journal, Volume 5, Issue 2.

3- Anderson, J. R., Guan, Y., \& Koc, Y. (2016),"The academic adjustment scale: Measuring The Adjustment of Permanent Resident or Sojourner Students". International Journal of Intercultural Relations, Vol. 54.

4- Arjanggi, R., \& Kusumaningsih, L. P. S. (2016), "The Correlation between Social Anxiety and Academic Adjustment among Freshmen". Procedia - Social and Behavioral Sciences. Volume 219.

5- Basmah Al-Shareef (2014): "Counselling Program in Effective Study Methods and its Impact on Improving Academic Adjustment among Jordan University students", Educational Sciences Studies, Volume 41, Issue 2, University of Jordan.

6- Firas Yaseen Al-Qa'dan (2018): “The Effect of a Training Counselling Program in Reducing Stress and Improving the level of Academic Adaptation for students at Preparatory Year Program Hai'I University" Journal of Educational and Psychological Sciences, Volume 2, Issue 9, National Research Center, Gaza.

7- Hamed Zahran (2005): Psychological Health and Psychotherapy, issue no. 4, Alam Al-Kotob, Cairo.

8- Hamed Zahran (2005): Guidance and Psychological Counselling, issue no. 4, Alam Al-Kotob, Cairo. 
9- Ibrahim Sarayrah (2016): "Effectiveness of Collective Counselling Program for the Low Adapt of new Students with Campus life at the University of Mutah", masters, unpublished, Mu'tah University, Jordan.

10- Javier Sánchez-Rosas and others (2017), “A Scale Assessing Social Academic Participation in Class for University Students", International Journal of Psycho-Educational Sciences, Volume 6, Issue no.1.

11- Jasim Al-Abidi and Alaa Al-Abidi (2010): Counselling and Psychological Guidance, Debono Publish and Distribution House, Jordan.

12- Mahmoud Al-Tamimi (2016): University Counselling, De Bono Center for Teaching Thinking, Emirates.

13- M.El-Araby Shamoun and Magda Ismail (2017), "Guidance and Psychological Counselling in Sports Field", Modern Book Centre, Cairo.

14- M.El-Araby Shamoun and Magda Ismail (2018), "Self-Talk and Performance Development in Sports Competitions", Modern Book Centre, Cairo.

15- Rafida Al-Harira and Samira Al-Emami (2011): Psychological and Educational Counselling in Educational Institutions, Al-Masira Publish House, Jordan.

16-Saleh Al-Dahiri (2008): "Basics of Psychological Adjustment,

Behavioral and Emotional Disorders, Basics and theories", Safaa Publish House, Oman.

17- Sandra Meriden, translated by William Ebid, Abdulrahman Ahmed (1994): Success in University Education, Kuwait. 18-Thae'r Hassan, Saleh Mahdi (2008): "Effectiveness of Educational Counselling Program to increase Adjustment with University Life 
for Faculty of Physical Education Students", Physical Education

Sciences Journals, first volume, issue no. 9, Babel University, Iraq.

19-Waslullah Al-Sawat, Ghaleb Al-Mashikhi (2011): "Effect of

counselling Program in Adapting to Academic Life of the new

Students at Tail University", Al-Tarbih Journal, Volume 1, Issue 145,

Faculty of Education, Al-Azhar University. 